\section{Futebol e política no mundo lusófono}

Futebol e política estão associados de maneira estreita e profunda desde o surgimento dessa modalidade esportiva, hoje mundialmente popular. Ao enfocar o mundo lusófono, marcado por intenso entusiasmo pelo futebol, surgem ideias muito interessantes sobre as linhas de desenvolvimento histórico de suas nações, sociedades e culturas. No universo atual do futebol, também se refletem crises sociais e políticas, bem como cisões do presente.

O futebol sempre foi e ainda é uma questão política num sentido positivo e negativo; por um lado, a profissionalização do esporte nas primeiras décadas do século XX fez com que certas barreiras de classe e de "raça" se rompessem; por outro, regimes autoritários ou totalitários, com grande frequência, não medem esforços em instrumentalizar e ideologizar esse esporte preferido das massas, seja como "ópio do povo", seja na forma de carregarem suas seleções nacionais com sentido ufanista. Ao mesmo tempo, o futebol sempre foi um instrumento de protesto e de resistência política, e até mesmo objeto de reflexão político-filosófica sobre o chamado "futebol de direita e de esquerda".

Tomada em sentido mais amplo, a política também permeia o futebol e suas culturas, e pode ser investigada com base em discussões históricas e atuais. Exemplos disso seriam certos aspectos, como a "política" de transferência de clubes no futebol globalizado, a transformação de "heróis" tradicionais em "ídolos" globais, bem como o conflito entre torcedores tradicionais e a crescente comercialização do jogo.

O futebol apresenta um paradoxo aparente: enquanto jogo, prescinde de palavras para desenvolver os seus significados. No entanto, esse jogo é rodeado e atravessado por uma rede complexa de vozes, enunciados e discursos que constituem, continuamente, a sua importância cultural e social. Compreendido como "fenômeno social total" (Marcel Mauss), o futebol reúne em si uma série de vozes: as vozes de seus atores e agentes - jogadores, técnicos, árbitros etc. -, as vozes da assistência - torcedores em geral, torcidas organizadas etc. 
-, e as vozes da mídia - Rádio, Imprensa, TV, redes sociais etc. Tais vozes podem ganhar expressão também na literatura, na música e nas artes.

O Dossiê da presente edição da FuLiA / UFMG com o título Futebol E POLítica no Mundo LuSófono nasceu da seção temática "Futebol e política", organizada pelos editores no âmbito do XII Congresso Alemão de Lusitanistas, realizado de 13 a 16 de setembro de 2017 na Universidade Johannes Gutenberg, em Mainz, Alemanha. Gostaríamos de agradecer a todos os participantes pela experiência enriquecedora de três dias com comunicações interessantes e discussões instigantes, como também pelas contribuições que pudemos reunir aqui.

Os textos que compõem este dossiê refletem sobre a relação entre o futebol e a política no mundo lusófono a partir de uma perspectiva específica, bem como inter ou transdisciplinar. Esperamos que o seu conjunto possibilite não só o diálogo entre abordagens culturalistas, linguísticas e sociais, mas também um olhar comparativo para o futebol em suas diversas dimensões nacionais e regionais da Lusofonia.
Porque, por seu caráter transdisciplinar e polifônico, o futebol enquanto objeto de estudo em sua relação com a política permite uma série de possibilidades, potencializadas no universo lusófono, em que há "uma língua" e "muitas vozes".

Em "A luta pelo Passe Livre: Das politische Handeln des brasilianischen Fußballers Afonso Celso Garcia Reis in den 1960er und 1970er Jahren" ("A atitude política do jogador brasileiro Afonso Celso Garcia Reis e sua luta pelo Passe Livre nos anos 1960 e 1970"), Sebastian Knoth analisa como Afonsinho, no âmbito da radical mudança nos padrões de treinamento e da imposição de um modelo de disciplina militar no futebol brasileiro, iniciou a luta pelo passe livre, que se tornou uma ação simbólica contra as repressões da ditadura militar no Brasil. A repercussão social deste conflito foi um fator político importante naquele momento e ultrapassou em muito os limites do mundo do futebol.

Por sua vez, Thomas Weissmann contribui para o presente dossiê com o artigo "Die frühe Sportpolitik des portugiesischen Estado Novo im Spiegel der Vereinspresse" ("A antiga política 
desportiva do Estado Novo português no espelho da imprensa do clube"), no qual analisa como a imprensa clubista lisboeta respondia à implementação do esporte português independente na organização do Estado Novo, nos anos 1940, conseguindo combinar a argumentação oficial sobre a tarefa dos clubes na educação física do povo português com a defesa de uma maior liberdade dos clubes, para construir assim uma narrativa nacionalista de ampliação das margens da política clubista nos limites da ditadura.

Em “FFF versão 2.0: uma possível actualização dos três Fs associados ao Estado Novo", Cláudia Fernandes estuda a associação comum de Fado, Fátima e Futebol ao Estado Novo português como uma forma de manipulação do povo e manobra de política internacional, assim como a volta surpreendente e vitoriosa dessa conjugação no presente, formando - ou não? - uma nova versão dos FFF ou, inclusive, um novo paradigma cultural.

Em "Futebol, política e identidade no Brasil", Marcel Vejmelka estuda o futebol no Brasil como elemento decisivo para a esfera política, que, no nível da micropolítica, articula grande parte das dinâmicas sociais e culturais, da identificação individual e coletiva até as mais variadas formas de comunicação e codificação midiática. 0 autor considera o futebol um dos veículos privilegiados e um dos campos mais cobiçados para a concepção e concretização de identidades clubísticas, locais e regionais, culminando com propostas identitárias nacionais do Brasil na sua autopercepção enquanto "país do futebol" e pátria do "melhor futebol do mundo".

Outra contribuição para o presente dossiê é o artigo de Augusto Sarmento-Pantoja, "O futebol e as ditaduras nos tempos do Condor", no qual o autor demonstra como o documentário Memórias do Chumbo: o futebol nos tempos do condor, de Lúcio de Castro, articula o terrorismo de Estado às ditaduras no Brasil, Uruguai, Argentina e Chile, associando-os a algumas representações do controle estatal no futebol e tentando compreender o papel da ditadura brasileira como a fomentadora dos demais regimes do Cone Sul através da Operação Condor. 
Para as suas reflexões em "O mito de Pelé, ou: 'um desvendamento do Ser"', Clemens van Loyen parte do ensaio "Peleologia", de Vilém Flusser, de 1964, argumentando que tal ensaio está no limiar do próprio esclarecimento sobre o conceito de 'pós-história', e visando elucidar as teias de pensamento, a dissolução e o surgimento de conceitos na obra flusseriana. Em Pelé, Flusser reconhece uma nova possibilidade de existência, o assim chamado 'novo homem', que seria também um modelo de vida para os brasileiros.

O dossiê conta também com o artigo "O time como comunidade luminosa: A turma da Rua Quinze e Aventura no Império do Sol", no qual Tania Sarmento-Pantoja analisa os romances de Marçal Aquino e, respectivamente, Silvia Cintra Franco a respeito da incorporação do jogo - no caso do futebol e do voleibol - ao cotidiano dos personagens como "elemento estruturante" de uma educação para a vida e à formação de uma "comunidade luminosa".

Por sua vez, Elcio Loureiro Cornelsen, no artigo “'Tudo em família com a Paz do Senhor' - certa vez, no Estádio Salazar", reflete sobre a relação entre futebol e política a partir da análise de três crônicas esportivas publicadas no Jornal dos Sports, no contexto da partida amistosa reunindo a Seleção Brasileira e a Seleção Portuguesa, que celebrou a inauguração do Estádio Salazar, em 1968, na cidade de Lourenço Marques (atual Maputo), então capital de Moçambique sob o domínio colonial português, mostrando como a polifonia produzida por essas crônicas revela que o futebol, para além do campo esportivo, nem sempre está alheio ao contexto político.

Na seção Entrevista, "Conversa com Aldyr Schlee (parte II): a criação da camisa canarinho e seu recente uso político", Gustavo Cerqueira Guimarães e Giulia Piazzi dão continuidade à documentação dos interessantes e valiosos depoimentos do escritor, jornalista, professor e desenhista Aldyr Garcia Schlee, falando de um de seus méritos de maior significação símbolico-cultural na história do futebol brasileiro: a criação do novo uniforme da seleção brasileira de futebol, da lendária "camisa canarinho", em 1953. Também abordam o recente uso político da camisa nas manifestações populares, vinculadas ao golpe. 
Na seção Paralelas, a historiadora Juliana da Silva Pinto Carneiro constrói o seu ensaio "O lugar da cultura nos Jogos Olímpicos: uma análise dos Jogos de Berlim (1936)" a partir da compreensão que os programas de cultura são um campo privilegiado para a consolidação dos aspectos simbólicos presentes nas edições destes megaeventos. Na primeira parte, a autora apresenta um breve panorama temporal, estruturado a partir de três momentos: de 1896 a 1912, quando as artes e a cultura não estavam formalmente inseridas nos Jogos Olímpicos; de Estocolmo 1912 a Londres 1948, que incluíam competições das artes olímpicas; e de Melbourne 1956 a Barcelona 1992, implicando diferentes concepções de programação cultural. Na segunda parte, Juliana Carneiro investiga mais detidamente os Jogos de Berlim (1936), partindo da premissa que o governo alemão entendeu a "força simbólica dos elementos culturais" e a potencializou com estratégias de propaganda para consolidar as principais representações do modelo nazista.

Na seção Resenhas, Lucas Toledo Gonçalves apresenta "Futebol e ditadura militar no Brasil: o episódio brasileiro da série Memórias do Chumbo: o futebol nos tempos do Condor", documentário produzido em 2012 pelo jornalista e historiador Lúcio de Castro. 0 episódio contextualiza a temática ante o fundo histórico das conjunturas políticas internas e externas que levaram ao golpe de 1964 assim como dos primeiros anos do regime militar, para enfocar a relação entre futebol e ditadura militar nos exemplos das Copas do Mundo de 1966 e 1970, e detendo-se, por exemplo, nos casos de João Saldanha, Afonsinho, João Havelange e Pelé, para finalizar com a ligação entre a Operação Condor e o futebol.

A seção Poética, dedicada às múltiplas possibilidades das abordagens artísticas do futebol e do mundo dos esportes, reúne nesta edição a série de cartazes, desenhados originalmente em formato de papel A2, intitulada "O legado da Copa 2014 foi o riso", do artista belo-horizontino Alexandre Junior, evidenciando uma vez mais a capacidade de os brasileiros transformarem em piada uma experiência tão traumática como o famigerado 7 a 1 da Alemanha contra o Brasil. As fotografias do projeto de inclusão social "Revolución Pelota", dos ativistas argentinos Facundo Leiton, Federico 
Pería, Matías Asconapé e Matías Perrone mostram a força político-social do futebol na sua dimensão mais impactante e positiva: a alegria, a esperança e a valorização que este esporte consegue criar no trabalho com crianças e adolescentes. Do mundo visual, passamos para o poema sonorizado "Bola que balança a rede humana", de Wagner Moreira, de lá para o díptico “Cartão amarelo" | "Cartão vermelho", de Gustavo Cerqueira Guimarães, e fechamos com o poema em diálogo com o futebol "À beira-mar", de Ana Martins Marques.

Terminamos a preparação da presente edição da revista FuLiA / UFMG poucos dias antes do início da Copa do Mundo na Rússia - torneio também fortemente marcado pela dimensão política do futebol -, num processo de leituras, redação, revisão e correspondências trocadas entre o Brasil e a Alemanha, salpicando todas essas tarefas com os costumeiros comentários, palpites e discussões a respeito das chances ou expectativas de cada seleção, dos últimos amistosos preparativos, do desempenho desse ou daquele jogador. Provavelmente, acaba sendo assim mesmo: estudar o futebol em termos acadêmicos é tarefa séria, como também o é o futebol na sua importância comercial, cultural e política. Ao mesmo tempo, igual ao futebol que, afinal, "não é mais que um jogo", não é possível se dedicar ao "ludopédio" como pesquisador e professor sem a paixão do aficionado e torcedor. Esperamos que esta paixão se manifeste também nas contribuições para o estudo do futebol aqui reunidas.

Desejamos a todos uma boa leitura e uma ótima Copa!

Belo Horizonte, 11 de junho de 2018.

Elcio Loureiro Cornelsen Faculdade de Letras da UFMG/Brasil Bolsista de Produtividade em Pesquisa do CNPq

Marcel Vejmelka

Universidade de Mainz/Alemanha 